This report has been reproduced directly from the best available copy.

Available to DOE and DOE contractors from the Office of Scientific and Technical Information, P.O. Box 62, Oak Ridge, TN 37831; prices available from (615) 576-8401, FTS 626-8401.

Available to the public from the National Technical Information Service, U.S. Department of Commerce, 5285 Port Royal Rd., Springfield, VA 22161.

This report was prepared as an account of work sponsored by an agency of the United States Government. Neither the United States Government nor any agency thereof, nor any of their employees, makes any warranty, express or implied, or assumes any legal liability or responsibility for the accuracy, completeness, or usefulness of any information, apparatus, product, or process disclosed, or represents that its use would not infringe privately owned rights. Reference herein to any specific commercial product, process, or service by trade name, trademark, manufacturer, or otherwise, does not necessarily constitute or imply its endorsement, recommendation, or favoring by the United States Government or any agency thereof. The views and opinions of authors expressed herein do not necessarily state or reflect those of the United States Government or any agency thereof. 


\section{DISCLAIMER}

Portions of this document may be illegible in electronic image products. Images are produced from the best available original document. 
ORNL/TM-13009

Dist. Category UC-426

Fusion Energy Division

\title{
PARTICLE EXHAUST OF HELIUM PLASMAS WITH ACTIVELY COOLED OUTBOARD PUMP LIMITER ON TORE SUPRA
}

\author{
T. Uckan, T. Loarer, ${ }^{\dagger}$ M. Chatelier, ${ }^{\dagger}$ D. Guilhem, ${ }^{\dagger}$ T. Lutz, $^{+}$M. A. Mahdavi, ${ }^{+}$ \\ P. K. Mioduszewski, and R. E. Nygren ${ }^{+}$
}

\footnotetext{
†Centre d'Etudes de Cadarache, St Paul-lez-Durance, France

+ Sandia National Laboratories, Albuquerque, NM

${ }^{+}$General Atomics, San Diego, CA
}

This is a preprint of a paper presented at the 22nd EPS Conference on Controlled Fusion and Plasma Physics, July 3-7, 1995, Boumemouth, United Kingdom and to be printed in the Proceedings.

Date Published: August 1995

\author{
Prepared for the \\ Office of Fusion Energy \\ Budget Activity No. AT 10 \\ Prepared by \\ OAK RIDGE NATIONAL LABORATORY \\ Oak Ridge, Tennessee 37831 \\ managed by \\ LOCKHEED MARTIN ENERGY SYSTEMS, INC. \\ for the \\ U.S. DEPARTMENT OF ENERGY \\ under contract DE-AC05-84OR21400
}




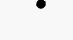




\section{CONTENTS}

Page

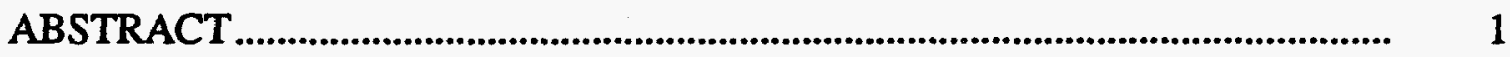

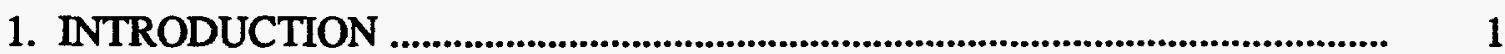

2. PUMP LIMITER CHARACTERISTICS AND DIAGNOSTICS........................ 2

3. EDGE PLASMA PAPAMETERS AND PARTICLE COLLECTION ............... 3

4. PARTICLE BALANCE AND HELIUM EXHAUST ..................................... 5

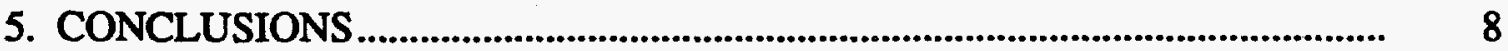

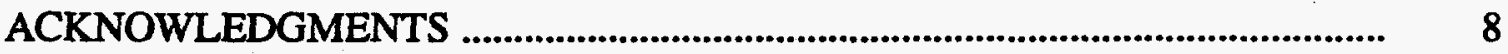

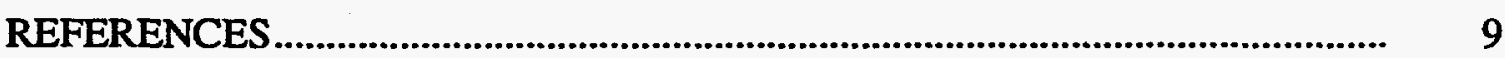




\title{
PARTICLE EXHAUST OF HELIUM PLASMAS WITH ACTIVELY COOLED OUTBOARD PUMP LIMITER ON TORE SUPRA
}

\author{
T. Uckan \\ T. Lutz \\ T. Loarer \\ M. A. Mahdavi \\ M. Chatelier \\ P. K. Mioduszewski \\ D. Guihem \\ R. E. Nygren
}

\begin{abstract}
The superconducting tokamak Tore Supra was designed for long-pulse (30-s) high input power operation. Here observations on the particle-handling characteristics of the actively cooled modular outboard pump limiter (OPL) are presented for helium discharges. The important experimental result was that a modest pumping speed $\left(1 \mathrm{~m}^{3} / \mathrm{s}\right)$ of the OPL turbomolecular pump (TMP) provided background helium exhaust. This result came about due to a wellconditioned vessel wall with helium discharges that caused no wall outgasing. The particle accountability in these helium discharges was excellent, and the well-conditioned wall did not play a significant role in the particle balance. The helium density control, $25 \%$ density drop with OPL exhaust efficiency of $\sim 1 \%$, was possible with TMP although this may not be the case with reactive gases such as deuterium. The observed quadratic increase of the OPL neutral pressure with helium density was consistent with an improvement of the particle control with increasing plasma density.
\end{abstract}

\section{INTRODUCTION}

Steady-state operation of magnetic fusion plasmas requires active control of both heat and particles. The superconducting tokamak Tore Supra was designed for long-pulse (30-s) high heating power discharges. Actively cooled plasma facing components, such as modular pump limiters, are used for power-handling and particle exhaust. This paper reports experimental observations on the particle-handling characteristics of the Tore Supra actively cooled modular outboard pump limiter (OPL) [1]. The important experimental result was that a modest pumping speed ( $\left.1 \mathrm{~m}^{3} / \mathrm{s}\right)$ of the OPL turbomolecular pump (TMP) provided the background helium pumping even though the particle control with pump limiters generally 
requires a pumping speed at least close to the neutral backflow conductance of the pump limiter throat, which is $\sim 5 \mathrm{~m}^{3} / \mathrm{s}$ for the OPL. This result came about due to a wellconditioned vessel wall with helium discharges that caused no wall outgasing.

\section{PUMP LIMITER CHARACTERISTICS AND DIAGNOSTICS}

For long-pulse operation, the pump limiter head must be equipped with active cooling. The design of a pump limiter is always a compromise between a thin limiter head for high particle exhaust and a leading edge (LE) that is sufficiently recessed to be in a region of tolerable heat flux. The present active cooling technology of heat removal can handle typically $5 \mathrm{MW} / \mathrm{m}^{2}$ on average and $20 \mathrm{MW} / \mathrm{m}^{2}$ maximum effectively. At the leading edge of the limiter module, the cooling channel determines the thickness of the limiter head. With this in mind, the OPL design was optimized for particle collection to control the plasma density effectively, and the two-sided collection of the scrape-off layer (SOL) ion flux is ensured by lateral throats recessed by $\mathrm{r}_{\mathrm{LE}}=2.5 \mathrm{~cm}$ from the last closed flux surface (LCFS) with an opening of $\Delta=2.5 \mathrm{~cm}$ (Fig. 1).

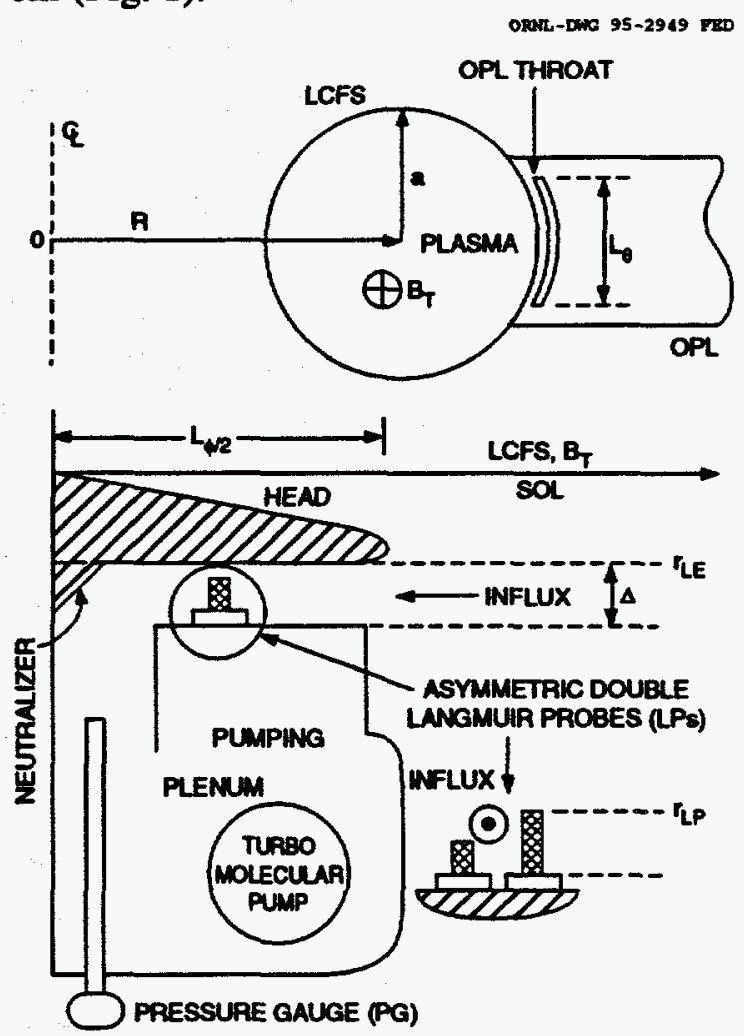

Fig. 1. Schematic of the two-sided Tore Supra OPL (only one side is shown) and its diagnostics, namely LPs and PGs. Here the dimensions are $r_{L E}=\Delta=2.5 \mathrm{~cm}, L_{\phi}=0.5 \mathrm{~m}$, and $L_{\theta}=0.6 \mathrm{~m}$. The turbomolecular pump has a pumping speed of $\sim 1 \mathrm{~m}^{3} / \mathrm{s}$. 
The toroidal and poloidal extents of the OPL are $\mathrm{L}_{\phi}=0.5 \mathrm{~m}$ and $\mathrm{L}_{\theta}=0.6 \mathrm{~m}$, respectively. The limiter head is made of cooling tubes brazed with pyrolytic graphite tiles for removing a total steady-state power load of $1.5 \mathrm{MW}$. The OPL is equipped with a titanium getter pump with a speed of $\sim 50 \mathrm{~m}^{3} / \mathrm{s}$ for reactive gases and a turbomolecular pump of $1 \mathrm{~m}^{3} / \mathrm{s}$ that provides background pumping as well as pumping of nable gases like helium. The OPL diagnostics are a set of asymmetric double Langmuir probes (LPs) located on both the ion drift and the electron drift sides of the pump limiter throat entrance. The Langmuir probes are $r_{L P}=3.3 \mathrm{~cm}$ radially away from the LCFS and are used for measuring the throat electron density $n_{e}$, the temperature $T_{e}$, and the particle flux e-folding length $\lambda_{\Gamma}$.In addition, the pressure gauges (PGs) connected into both the ion drift and the electron drift sides of the pumping plenum of the module (Fig. 1) measure the neutral particle pressure po resulting

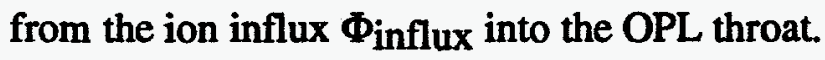

\section{EDGE PLASMA PARAMETERS AND PARTICLE COLLECTION}

The OPL experiments were performed with helium plasmas to prevent wall particle saturation (the inboard limiter is made of $12-\mathrm{m}^{2}$ graphite tiles, which can contain 100 to 1000 times the total plasma content [2]) and the corresponding difficulties with plasma density control. During these experiments only the turbomolecular pump was activated. The discharge was initiated on the inboard limiter, later moving it to the OPL at $t=3 \mathrm{~s}$ after the startup, and keeping the plasma there at about $\Delta \mathrm{t}=10 \mathrm{~s}$ during the steady-state conditions. The ohmically heated discharge parameters for this series of experiments were as follows: major radius, $2.4 \mathrm{~m}$; core plasma radius, $0.725 \mathrm{~m}$; toroidal magnetic field, $3.8 \mathrm{~T}$; plasma current, $\mathrm{I}_{\mathrm{p}}=1.45 \mathrm{MA}$; and ohmic heating power, $1.45 \mathrm{MW}$. The OPL throat plasma and the pumping plenum neutral particle characteristics were measured with the Langmuir probes and the pressure gauges. Here the results are presented during the density scan, namely the line average core plasma density $\bar{n}_{e}=(3$ to 5$) \times 10^{19} \mathrm{~m}^{3}$ obtained using density feedback by controlling the helium injection into the discharge for compensating the exhaust of the OPL with the turbomolecular pump. In Fig. 2(a) the OPL throat $n_{e}$ and in Fig 2(b) the corresponding $T_{e}$ are presented as functions of $\bar{n}_{e}$. As expected, $T_{e}$ decreases with $\bar{n}_{e}$, whereas $n_{\mathcal{e}}$ increases. However, there is an asymmetry between the ion drift and the electron drift sides of the OPL. This asymmetry was also observed with diagnostics of the heat deposition on the limiter head with the infrared camera and the water calorimetry measurements. The SOL characteristic scale length $\lambda_{\Gamma}$ is given in Fig. 2(c), and $\lambda_{\Gamma}$ slightly increases with $\bar{n}_{e}$. The neutral helium pressure po in the OPL plenum is shown in Fig. 2(d), and $p_{0}$ increases quadratically with $\bar{n}_{e}$, reaching $p_{0}=3 \mathrm{mTorr}$ for $\Phi_{\text {influx }} \approx 25$ Torr-L/s at $\overline{\mathrm{n}}_{\mathrm{e}}=5 \times 10^{19} \mathrm{~m}^{-3}$. 

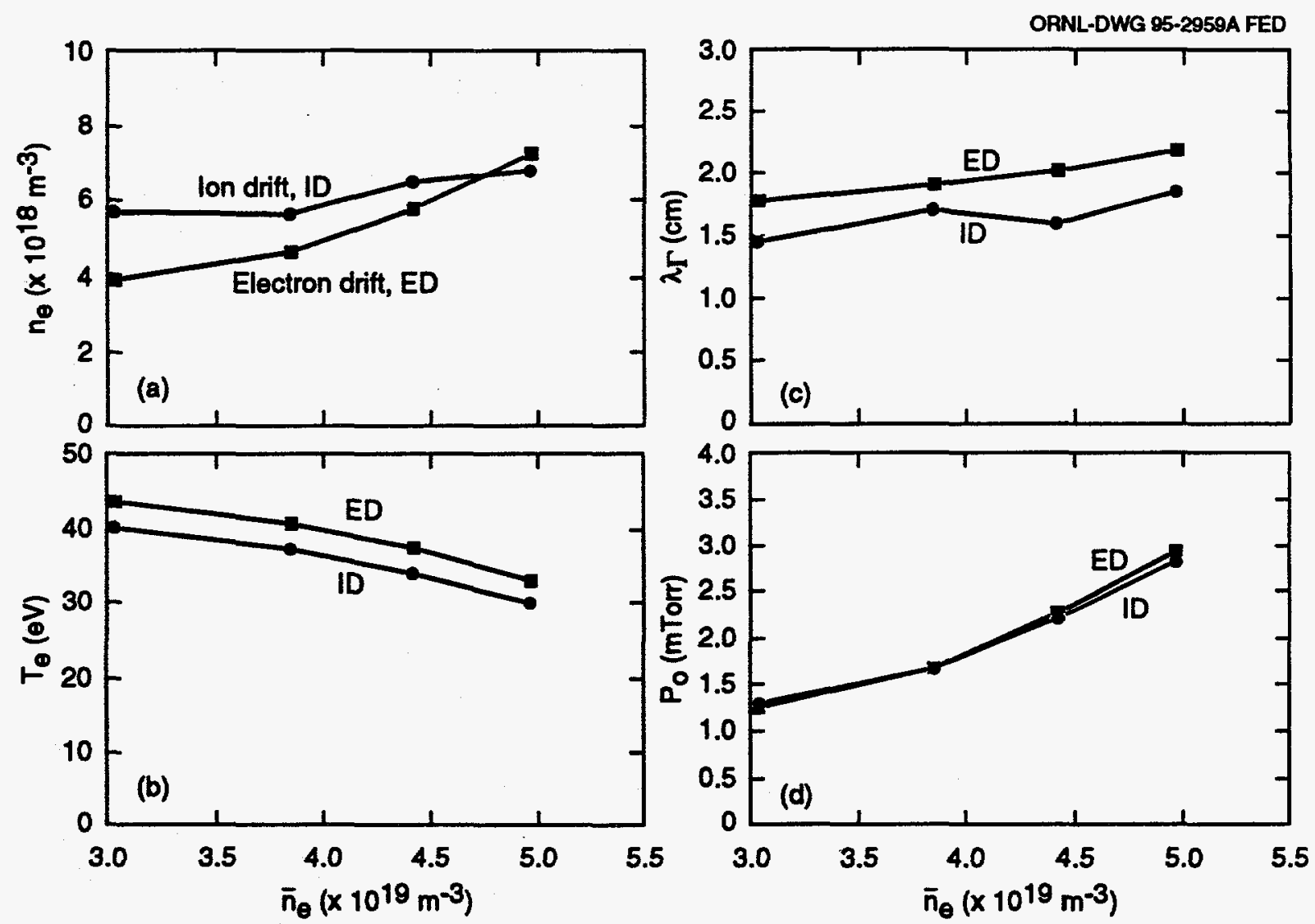

Fig. 2. Variations of (a) $n_{e},(b) T_{e}$, (c) $\lambda_{\Gamma}$ of OPL throat plasma, and (d) neutral pressure $p_{0}$ in pumping plenum with core plasma $\overline{\mathbf{n}}_{\mathbf{e}}$.

The quadratic increase of po with $\overline{\mathrm{n}}_{\mathrm{e}}$ is similar to observations made in Tore Supra with deuterium [3,4] and also in high recycling D-III divertor plasmas [5]. To access the particle collection characteristics of the OPL, the collection efficiency $\varepsilon_{\text {coll }}=\Phi_{\text {influx }} / \Phi_{\text {sol }}[6]$ is calculated. Here $\Phi_{\text {sol }}=\Gamma_{0} \times L_{\theta} \times \lambda_{\Gamma}$ is the total number of SOL particles within the flux tube, defined by the OPL, $\Gamma_{0}=0.5 \mathrm{cs}_{s} \times \mathrm{n}_{\mathrm{e}} \times \exp \left(\mathrm{nLP}_{\mathrm{P}} / \lambda_{\Gamma}\right)$ is the particle flux at the LCFS, and $c_{s}=\left(T_{e} / m_{i}\right)^{0.5}$ is the ion sound speed. Using the Langmuir probe results, the particle collection efficiency is estimated as $\varepsilon_{\text {coll }}=20 \%$, Fig. 3, which is consistent with the OPL design value for $r_{L E}=2.5 \mathrm{~cm}$ and $\lambda_{\Gamma}=2 \mathrm{~cm}$. 


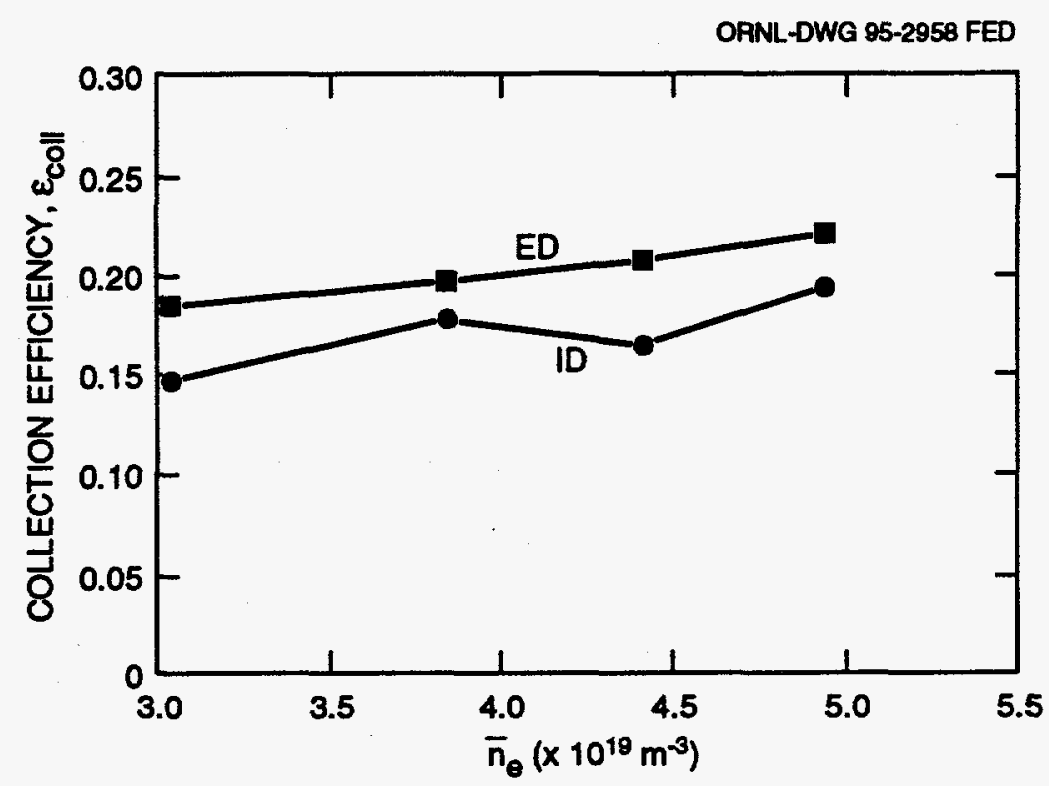

Fig. 3. Collection efficiency of the OPL core plasma $\bar{n}_{e}$.

\section{PARTICLE BALANCE AND HELIUM EXHAUST}

Using the particle conservation, the particle balance of the helium discharge is written as $\int \Phi_{\text {inj }} d t=\int S_{\text {eff }} N_{L} d t+N_{e} / 2+N_{L} V_{L}$, where $\Phi_{\text {inj }}$ is the helium injection rate, $N_{L}$ is the number of helium neutrals in the OPL plenum, $S_{\text {eff }}$ is the effective pumping speed, $N_{e}$ is the total number of plasma electrons, and $V_{L}$ is the volume of the OPL pumping plenum $\left(3 \mathrm{~m}^{3}\right)$. Moreover, the time integration here is from the start of the discharge $t=0$ to any time less than the end of the discharge $(t=13 \mathrm{~s})$. Here the contribution of impurities and also any desorbed deuterium to the plasma density are ignored because these discharges followed a long series of 30 helium discharges of about 10 to $15 \mathrm{~s}$; these provided a substantial helium "preconditioning" to remove surface deuterium from the vessel wall. Figure 4 shows the resulting time evolution of the particle balance. As observed, the particle balance is quite good since nearly all the particles are recovered in the discharge. Also, with helium discharges, the wall particle content is negligible and does not appear in the particle balance. 


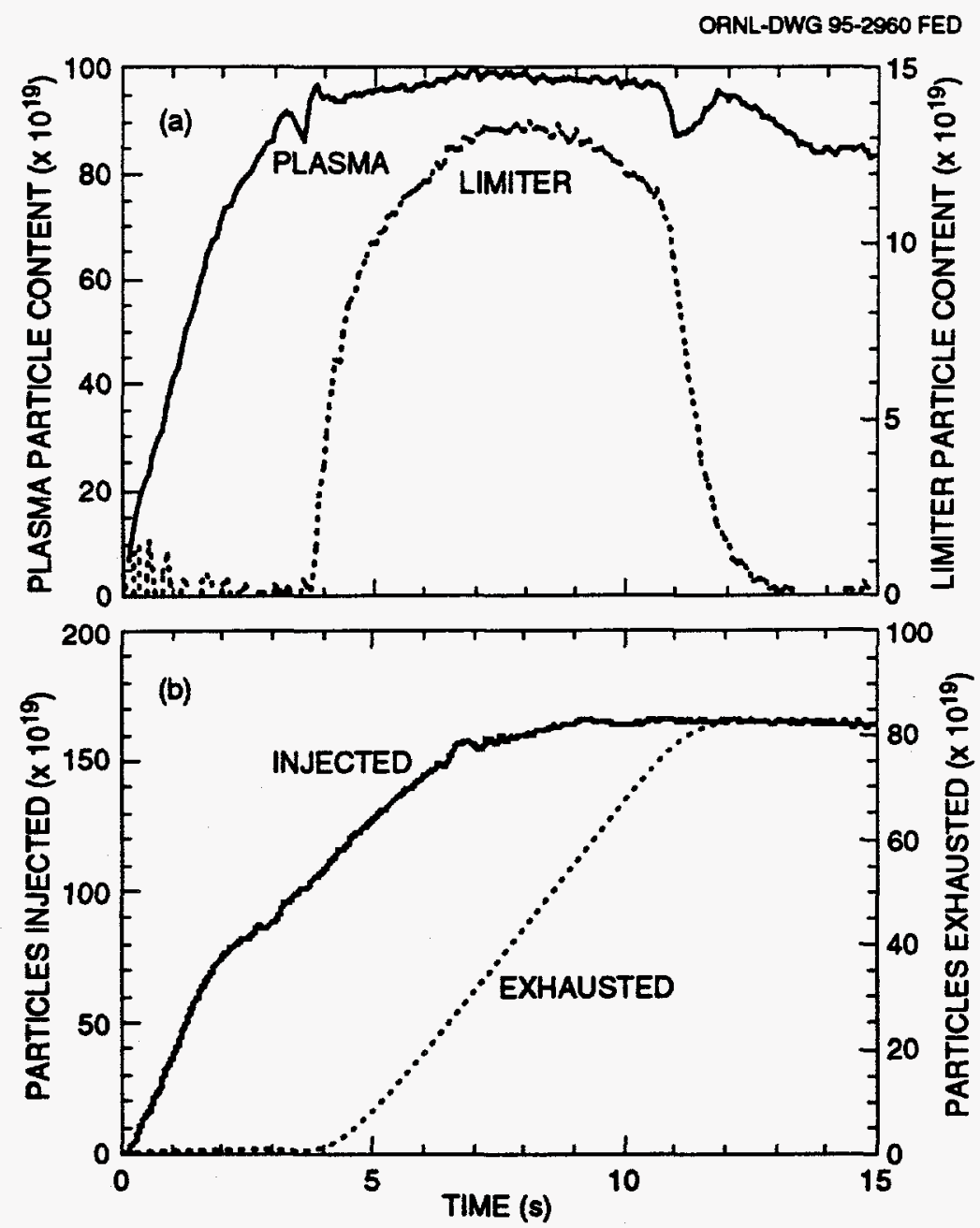

Fig. 4. Particle balance of helium discharge is well satisfied between (a) plasma and OPL plenum particle content and (b) injected and exhausted particles.

This result demonstrates that the particle balance for helium plasmas is well explained without including any effects from the wall. In other words, the wall particle content does not play a significant role in the particle balance, and the recycling coefficient is close to about $100 \%$ for helium discharges. This is not the case when the working gas is deuterium; then the wall reservoir becomes the most important contributor in the particle balance compared to the gas injection, the plasma content, the particle exhaust, and the pump limiter volume [2].

Next, the OPL particle exhaust experiment was carried out $\left(I_{p}=1.0 \mathrm{MA}\right.$, from 2.5 to $14 \mathrm{~s})$ by comparing the plasma density of two identical helium $\left(\Phi_{\mathrm{inj}}=0\right)$ discharges (here 
the global particle recycling coefficient $R_{\mathbf{n}}=1$ ) with and without the turbomolecular pump activated. Both discharges were initiated on the inboard limiter and shifted onto the OPL at $t$ $=3 \mathrm{~s}$; the time evolutions of plasma densities are shown in Fig. 5 (a). In spite of the low pumping speed of the turbomolecular pump ( $S_{\text {eff }}=1 \mathrm{~m}^{3} / \mathrm{s}$ ), helium exhaust was achieved at

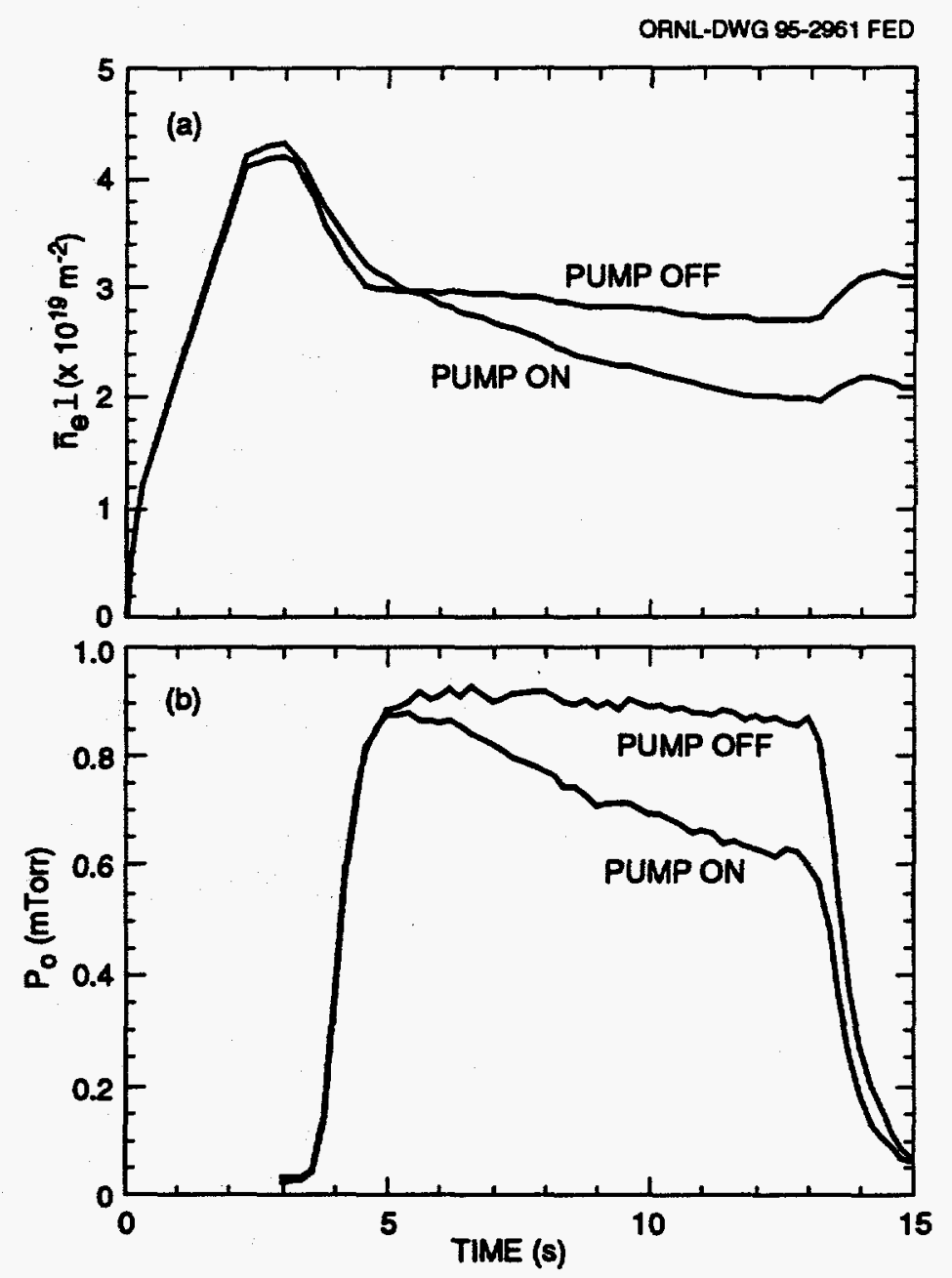

Fig. 5. Effects of OPL turbomolecular pump, $1 \mathrm{~m}^{3} / \mathrm{s}$ (off/on): (a) core helium line density and (b) po of pumping plenum.

a rate of $\Phi_{\text {exh }}=p_{0} \times S_{\text {eff }}=0.5$ Torr-L/s [Fig. 5 (b)]. The exhaust efficiency of the OPL is then estimated as $\varepsilon_{e x h}=\Phi_{e x h} /\left(N_{e} / \tau_{p}\right)[6]$, where $\tau_{p}$ is the global particle confinement time. From the plasma efflux $\mathrm{Ne}_{\mathrm{e}} / \tau_{\mathrm{p}} \approx 42$ Torr-L/s (typically $\tau_{\mathrm{p}} \approx 0.2 \mathrm{~s}$ [2]), the exhaust efficiency becomes $\varepsilon_{\text {exh }}=1.3 \%$ for these discharges. Nevertheless, this relatively low exhaust efficiency of the OPL had a significant effect on the core density, as shown in Fig 
5(a), resulting in a $25 \%$ helium plasma density $\left(n_{e}=2 \times 10^{19} \mathrm{~m}^{-3}\right)$ reduction. This observation can qualitatively be explained from the general particle balance by writing $N_{e}=\left(\Phi_{i n j}-d N_{e} / d t\right) \tau_{p} /\left(1-R_{n}+\varepsilon_{e x h}\right)$, and since $R_{n}=1$ due to well conditioned vessel

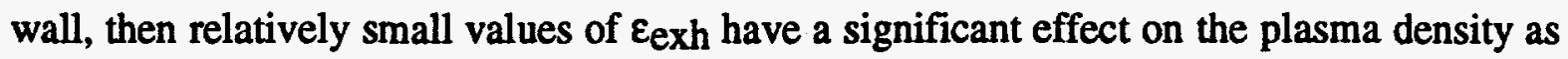
in the experiment $\left(\Phi_{i n j}=0\right)$.

\section{CONCLUSIONS}

Several important results from the OPL experiments are observed on the helium plasmas. First, the particle accountability in Tore Supra helium discharges is excellent for the present case. Second, the vessel wall was well conditioned and did not play a significant role in the particle balance during helium plasmas. Third, the density control in these helium discharges was possible with a modest pumping speed, $1 \mathrm{~m}^{3} / \mathrm{s}$, of the turbomolecular, although this may not be the case with reactive gases such as deuterium. Finally, the quadratic increase of the OPL neutral pressure with helium density indicates with an improvement of the particle control with increasing plasma density.

\section{ACKNOWLEDGMENTS}

The authors thank S. Vartanian for his continuous technical help. Research was sponsored by U.S. DOE under contract DE-AC05-84OR21400 with Lockheed Martin Energy Systems. 


\section{REFERENCES}

[1] R. Nygren et al., to be published in J. Nucl. Mater. (1995).

[2] C. Grisolia et al., J. Nucl. Mater. 196-198 281 (1992).

[3] M. Chatelier et al., 14th IAEA (1992).

[4] T. Loarer, in the proceeding of the 22nd EPS Conf. 1995.

[5] A. Mahdavi et al., Phys. Rev. Lett. 471602 (1981).

[6] T. Uckan et al., Fusion Tech. 13165 (1988). 

ORNL/TM-13009

Dist. Category UC-426

\section{INTERNAL DISTRIBUTION}

1. Director, Fusion Energy Division

2. D. B. Batchelor

3. L. A. Berry

4. B. A. Carreras

5. R. J. Colchin

6. J.H. Harris

7. D. L. Hillis

8. J. T. Hogan

9. R. C. Isler

10. T. C. Jernigan

11. C. C. Klepper
12. J. F. Lyon

13. P. K. Mioduszewski

14. M. Murakami

15. L. W. Owen

16-25. T. Uckan

26-27. Laboratory Records Department

28. Laboratory Records, ORNL-RC

29. Central Research Library

30. Document Reference Section

31. Fusion Energy Division Library

32. ORNL Patent Section

\section{EXTERNAL DISTRIBUTION}

33. Office of the Assistant Manager for Energy Research and Development, U.S. Department of Energy, ORO, Oak Ridge, TN 37831

34. J. D. Callen, Department of Nuclear Engineering, University of Wisconsin, Madison, WI 53706-1687

35. R. W. Conn, School of Engineering, University of California at San Diego, La Jolla, CA 92093-0403

36. N. A. Davies, Director, Office of Fusion Energy, Office of Energy Research, ER-50, U.S. Department of Energy, 19901 Germantown Road, Germantown, MD 20874-1290

37. S. O. Dean, Fusion Power Associates, Inc., 2 Professional Drive, Suite 248, Gaithersburg, MD 20879

38. R. W. Gould, Department of Applied Physics, California Institute of Technology, Pasadena, CA 91125

39. R. A. Gross, Plasma Research Laboratory, Columbia University, New York, NY 10027

40. D. M. Meade, Princeton Plasma Physics Laboratory, P.O. Box 451, Princeton, NJ 08543

41. M. Roberts, International Programs, Office of Fusion Energy, Office of Energy Research, ER-52, U.S. Department of Energy, 19901 Germantown Road, Germantown, MD 20874-1290

42. W. M. Stacey, School of Nuclear Engineering and Health Physics, Georgia Institute of Technology, Atlanta, GA 30332

43. D. Steiner, Nuclear Engineering Department, NES Building, Tibbetts Avenue, Rensselaer Polytechnic Institute, Troy, NY 12181

44. R. Varma, Physical Research Laboratory, Navrangpura, Ahmedabad 380009, India

45. Bibliothek, Max-Planck Institut für Plasmaphysik, Boltzmannstrasse 2, D-8046 Garching, Federal Republic of Germany

46. Bibliothek, Institut für Plasmaphysik, KFA Jülich GmbH, Postfach 1913, D-5170 Jülich, Federal Republic of Germany

47. Bibliothek, KfK Karlsruhe GmbH, Postfach 3640, D-7500 Karlsruhe 1, Federal Republic of Germany

48. Bibliothèque, Centre de Recherches en Physique des Plasmas, Ecole Polytechnique Fédérale de Lausanne, 21 Avenue des Bains, CH-1007 Lausanne, Switzerland

49. M. Chatelier, CEN/Cadarache, Departement de Recherches sur la Fusion Contrôlee, F-13108 Saint Paullez-Durance, France

50. D. Guilhem, CEN/Cadarache, Departement de Recherches sur la Fusion Contrôlce, F-13108 Saint Paullez-Durance, France

51. L. Laurent, CEN/Cadarache, Departement de Recherches sur la Fusion Contrôlée, F-13108 Saint Paullez-Durance, France

52. T. Loarer, CEN/Cadarache, Departement de Recherches sur la Fusion Contrôlée, F-13108 Saint Paul-lezDurance, France 
53. Bibliothèque, CEN/Cadarache, F-13108 Saint Paul-lez-Durance, France

54. Library, AEA Fusion, Culham Laboratory, Abingdon, Oxfordshire, OX14 3DB, England

55. Library, JET Joint Undertaking, Abingdon, Oxfordshire OX14 3EA, England

56. Library, FOM-Instituut voor Plasmafysica, Rijnhuizen, Edisonbaan 14, 3439 MN Nieuwegein, The Netherlands

57. Library, National Institute for Fusion Science, Chikusa-ku, Nagoya 464-01, Japan

58. Library, International Centre for Theoretical Physics, P.O. Box 586, I-34100 Trieste, Italy

59. Library, Centro Ricerche Energia Frascati, C.P. 65, I-00044 Frascati (Roma), Italy

60. Library, Plasma Physics Laboratory, Kyoto University, Gokasho, Uji, Kyoto 611, Japan

61. Plasma Research Laboratory, Australian National University, P.O. Box 4, Canberra, A.C.T. 2601, Australia

62. Library, Japan Atomic Energy Research Institute, Naka Fusion Research Establishment, 801-1 Mukoyama, Naka-machi, Naka-gun, Ibaraki-ken, Japan

63. G. A. Eliseev, I. V. Kurchatov Institute of Atomic Energy, P.O. Box 3402, 123182 Moscow, Russia

64. V. A. Glukhikh, Scientific-Research Institute of Electro-Physical Apparatus, 188631 Leningrad, Russia

65. I. Shpigel, Institute of General Physics, U.S.S.R. Academy of Sciences, Ulitsa Vavilova 38, Moscow, Russia

66. D. D. Ryutov, Institute of Nuclear Physics, Siberian Branch of the Academy of Sciences, Sovetskaya St. 5, 630090 Novosibirsk, Russia

67. O. Pavlichenko, Kharkov Physical-Technical Institute, Academical St. 1, 310108 Kharkov, Ukraine

68. Deputy Director, Southwestem Institute of Physics, P.O. Box 15, Leshan, Sichuan, China (PRC)

69. Director, The Institute of Plasma Physics, P.O. Box 26, Hefei, Anhui, China (PRC)

70. R. A. Blanken, Experimental Plasma Physics Research Branch, Division of Applied Plasma Physics, Office of Energy Research, ER-542, Germantown, U.S. Department of Energy, Washington, DC 20545

71. R. A. E. Bolton, IREQ Hydro-Quebec Research Institute, 1800 Montee-Ste.-Julie, Varennes, P.Q. JOL 2P0, Canada

72. R. L. Freeman, General Atomics, P.O. Box 85608, San Diego, CA 92186-9784

73. M. A. Mahdavi, General Atomics, P. O. Box 85608, San Diego, CA 92186-9784

74. K. W. Gentle, RLM 11.222, Institute for Fusion Studies, University of Texas, Austin, TX 78712

75. R. J. Goldston, Princeton Plasma Physics Laboratory, P.O. Box 451, Princeton, NJ 08543

76. J. C. Hosea, Princeton Plasma Physics Laboratory, P.O. Box 451, Princeton, NJ 08543

77. D. Markevich, Division of Confinement Systems, Office of Energy Research, ER-55, Germantown, U.S. Department of Energy, Washington, DC 20545

78. R. McKnight, Experimental Plasma Physics Research Branch, Division of Applied Plasma Physics, Office of Energy Research, ER-542, Germantown, U.S. Department of Energy, Washington, DC 20545

79. E. Oktay, Division of Confinement Systems, Office of Energy Research, ER-55, U.S. Department of Energy, 19901 Germantown Road, Germantown, MD 20874-1290

80. W. L. Sadowski, Fusion Theory and Computer Services Branch, Division of Applied Plasma Physics, Office of Energy Research, ER-541, U.S. Department of Energy, 19901 Germantown Road, Germantown, MD 20874-1290

81. J. W. Willis, Division of Confinement Systems, Office of Energy Research, ER-55, U.S. Department of Energy, 19901 Germantown Road, Germantown, MD 20874-1290

82. C. Alejaldre, Division de Fusion, CIEMAT, Avenida Complutense 22, E-28040 Madrid, Spain

83. Laboratory for Plasma and Fusion Studies, Department of Nuclear Engineering, Seoul National University, Shinrim-dong, Gwanak-ku, Seoul 151, Korea

84. J. L. Johnson, Plasma Physics Laboratory, Princeton University, P.O. Box 451, Princeton, NJ 08543

85. L. M. Kovrizhnykh, Institute of General Physics, Russia Academy of Sciences, Ulitsa Vavilova 38, 117924 Moscow, Russia

86. O. Motojima, National Institute for Fusion Science, Chikusa-ku, Nagoya 464-01, Japan

87. S. Okamura, Institute of Plasma Physics, Nagoya University, Chikusa-ku, Nagoya 464, Japan

88. V. D. Shafranov, I. V. Kurchatov Institute of Atomic Energy, P.O. Box 3402, 123182 Moscow, Russia

89. J. L. Shohet, Torsatron/Stellarator Laboratory, University of Wisconsin, Madison, WI 53706

90. H. Wobig, Max-Planck Institut für Plasmaphysik, D-8046 Garching, Germany 
91. F. S. B. Anderson, University of Wisconsin, Madison, WI 53706

92. R. F. Gandy, Physics Department, Auburn University, Auburn, AL 36849-3511

93. H. Kaneko, Plasma Physics Laboratory, Kyoto University, Gokasho, Uji, Japan

94. G. H. Neilson, Princeton Plasma Physics Laboratory, P.O. Box 451, Princeton, NJ 08543

95. S. Sudo, Plasma Physics Laboratory, Kyoto University, Gokasho, Uji, Japan

96. H. Yamada, National Institute for Fusion Science, Chikusa-ku, Nagoya 464-01, Japan

97. F. W. Perkins, Princeton Plasma Physics Laboratory, P.O. Box 451, Princeton, NJ 08543

98. T. Obiki, Plasma Physics Laboratory, Kyoto University, Gokasho, Uji, Kyoto, Japan

99. A. Tiyoshi, National Institute for Fusion Studies, Chikusa-ku, Nagoya 464-01, Japan

100. B. Richards, Fusion Research Center, University of Texas, Austin, TX 78712

101. W. L. Rowan, Fusion Research Center, University of Texas, Austin, TX 78712

102. A. J. Wootton, Fusion Research Center, University of Texas, Austin, TX 78712

103. T. Lutz, Sandia National Laboratories, P. O. Box 5800, Albuquerque, NM 87185-5800

104. R. E. Nygren, Sandia National Laboratories, P. O. Box 5800, Albuquerque, NM 87185-5800

105-106. Office of Scientific and Technical Information, P.O. Box 62, Oak Ridge, TN 37831

107-159. Given distribution as shown in DOE/OSTI-4500, Magnetic Fusion Energy (Category Distribution UC-426, Experimental Plasma Physics) 